\title{
Daytime sodium airglow emission measurements over Trivandrum using a scanning monochromator: first results
}

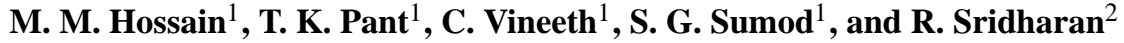 \\ ${ }^{1}$ Space Physics Laboratory, Vikram Sarabhai Space Centre, Trivandrum 695022, India \\ ${ }^{2}$ Physical Research Laboratory, Ahmedabad 380009, India
}

Received: 15 June 2010 - Revised: 2 November 2010 - Accepted: 4 November 2010 - Published: 9 November 2010

\begin{abstract}
This paper presents measurement of daytime Sodium (Na) airglow emissions at $589.6 \mathrm{~nm}$ wavelength using a ground based $1-\mathrm{m}$ scanning monochromator from Trivandrum $\left(8.5^{\circ} \mathrm{N}, 77^{\circ} \mathrm{E}, 0.5^{\circ} \mathrm{N}\right.$ dip latitude), a nearequatorial station in India. The Na emission intensity exhibits significant temporal variability within a day and from one day to another. The Na intensity has been compared with the daytime $\mathrm{OH}$ airglow intensity at $731.6 \mathrm{~nm}$ simultaneously measured using the unique Multiwavelength Dayglow Photometer (MWDPM). The temporal variabilities of the Na and $\mathrm{OH}$ intensities corroborate each other in most of the occasions without any appreciable time delay, although a small time delay up to $\sim 10 \mathrm{~min}$ has been observed at times. It appears that the variability of daytime $\mathrm{Na}$ emissions is influenced too by the photo-chemical excitations. The observed similarities in the $\mathrm{Na}$ and $\mathrm{OH}$ intensities are believed to be due to the similar roles played by $[\mathrm{O}]$ and $\mathrm{O}_{3}$ (in their photochemical excitations) and the dynamics occurring at about the same altitude region $(\sim 90 \mathrm{~km})$. It has also been found that the gravity waves play significant role in producing the short-scale oscillations in these emissions.
\end{abstract}

Keywords. Atmospheric composition and structure (Airglow and aurora; Middle atmosphere - composition and chemistry)

\section{Introduction}

Earth's atmosphere is known to have several metallic vapour layers, the first discovered among them was of sodium by Vesto Melvin Slipher (1929). The neutral atomic Na layer occurs globally in the upper mesosphere/lower thermosphere (MLT) region at an altitude $\sim 90 \mathrm{~km}$ and it has a thickness

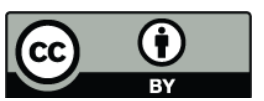

Correspondence to: M. M. Hossain (mosarraf_sw@yahoo.co.in) $\sim 10 \mathrm{~km}$. The major source of $\mathrm{Na}$ in the MLT region is the sporadic meteoroid ablation, although upward transport of water vapour from oceans is also considered as the other important source (Khomich et al., 2008). Meteoroid ablation occurs because of their very high entry velocities leading to rapid heating by collision with the air molecules. The frictional heating of the meteoroid is balanced by radiative losses, and by absorption of the heat energy through their temperature increase, melting, phase transitions and vaporization (Plane, 2004).

Above the atomic Na layer around $90 \mathrm{~km}$, ion chemistry predominates. Na atoms are ionized mainly by charge transfer with the ambient $\mathrm{NO}^{+}$and $\mathrm{O}_{2}^{+}$, although a small contribution comes from the solar photo-ionization. $\mathrm{Na}^{+}$is then neutralized by $\mathrm{N}_{2}$ to form the clusters, which undergo dissociative electron recombination and converts back to atomic $\mathrm{Na}$ (Plane, 2004). Below the atomic Na layer, $\mathrm{Na}$ converts into stable reservoir of $\mathrm{NaHCO}_{3}$ through a sequence of reactions. First, the in-situ generated $\mathrm{O}_{3}$ oxidizes $\mathrm{Na}$ atom to form $\mathrm{NaO}$, which in the presence of water vapor or hydrogen forms $\mathrm{NaOH}$. The $\mathrm{NaOH}$ combines with $\mathrm{CO}_{2}$ to form $\mathrm{NaHCO}_{3}$. The species, such as $\mathrm{NaO}, \mathrm{NaOH}$ and $\mathrm{NaHCO}_{3}$ are converted back to $\mathrm{Na}$ through the reactions with $\mathrm{O}$ and $\mathrm{H}$, and also by photolysis. Obviously the gas-phase metallic $\mathrm{Na}$ chemistry is closed, that is, all the constituent species cycle between each other, and no species provide a permanent sink for Na in the upper mesosphere (Plane, 2004).

In the MLT region, above and below the atomic Na layer sodium exists respectively in the form of ions (such as $\mathrm{Na}^{+}$, $\mathrm{NaN}_{2}^{+}$cluster, $\mathrm{NaO}^{+}$etc.) and chemical compound (such as stable $\mathrm{NaHCO}_{3}, \mathrm{NaO}$ etc.), which do not emit light. The neutral $\mathrm{Na}$ atoms that have large resonance scattering cross sections yield the daytime airglow emissions mainly through resonance scattering, although photochemistry may have some contribution. The well-known chemical scheme responsible for excitations of $\mathrm{Na}$ atoms is as follows (Chapman, 1939):

Published by Copernicus Publications on behalf of the European Geosciences Union. 
$\mathrm{O}+\mathrm{O}_{2}(+\mathrm{M}) \rightarrow \mathrm{O}_{3}(+\mathrm{M})$

$\mathrm{Na}+\mathrm{O}_{3} \rightarrow \mathrm{NaO}+\mathrm{O}_{2}$

$\mathrm{NaO}+\mathrm{O} \rightarrow \mathrm{Na}^{*}\left({ }^{2} \mathrm{P}\right)+\mathrm{O}_{2}$

$\mathrm{Na}^{*}\left({ }^{2} \mathrm{P}\right) \rightarrow \mathrm{Na}\left({ }^{2} \mathrm{~S}\right)+h v \quad(589.0$ and $589.6 \mathrm{~nm})$

where " $\mathrm{M}$ " denotes a third body, usually $\mathrm{N}_{2}$ molecule or $\mathrm{O}$ atom. It is obvious from the above reactions that the photochemistry can also control the daytime excitations of $\mathrm{Na}$ atoms and hence, the Na dayglow emissions.

Daytime ground based measurement of sodium airglow emissions is particularly difficult to perform. Because, intensity of the light available for resonant excitation of $\mathrm{Na}$ atoms is considerably less. This is obvious from its presence near the bottom of the very pronounced solar Fraunhofer absorption D line. Removal of Rayleigh and Mie scattered unwanted background light is also difficult. Hence the problem is to detect and measure the intensity of an emission line near the bottom of that absorption line, where the emission line intensity is at most equal to that of the residual scattered light and both combined are only one-tenth as strong as the nearby continuum (Blamont, 1961). Besides, the sodium emission lines are in the close neighbourhoods with the $5889 \AA, 5894 \AA$, $5895 \AA$ and $5901 \AA$ lines of the $\mathrm{OH}$ (8-2) band (Yarin et al., 1962a; Takahashi et al., 1981; Shefov and Piterskaya, 1984). This gives rise to difficulties in photometric measurements using narrow-band interference filters. Hence, it requires specialized techniques to measure the $\mathrm{Na}$ airglow emission intensities with significant signalto-noise ratio after elimination of solar background as well as the neighbouring $\mathrm{OH}$ lines.

There are many reports involving study of nighttime ground based $\mathrm{Na}$ airglow emissions (Clemesha et al., 1978, 1979, 1995; Kirchhoff et al., 1979; Sarkhel et al., 2009). However, there exist no recent systematic studies on daytime ground based $\mathrm{Na}$ airglow emissions. In this paper we have demonstrated a technique based on a 1-m scanning monochromator for ground based measurement of daytime sodium airglow emissions at $5896 \AA$ and compared it with the $\mathrm{OH}$ airglow emissions simultaneously measured using the unique Multiwavelength Dayglow Photometer (MWDPM) at Trivandrum $\left(77^{\circ} \mathrm{E}, 8.5^{\circ} \mathrm{N}, 0.5^{\circ} \mathrm{N}\right.$ dip latitude). Also in this study, the role of photochemistry has been considered to investigate the reason for similar variabilities in the $\mathrm{Na}$ and $\mathrm{OH}$ emissions.

\section{Experimental details}

A 1-m scanning monochromator (in Czerny-Turner configuration) augmented with a high diffraction efficiency $(\sim 70 \%)$ and high resolution plane holographic grating (groove density $2400 \mathrm{~g} \mathrm{~mm}^{-1}$, ruled area $102 \times 102 \mathrm{~mm}^{2}$ ), and an efficient reflecting optics is used in this study. Maximum resolution of the system achieved with this grating is $0.05 \AA$. The monochromator employs an image transfer system, which comprises of aspheric collimating and focusing mirrors, and axial entrance/exit slits. A photo-multiplier tube (PMT) with multi alkali cathode is used as the detector.

As mentioned in the previous section, this study is carried out from Trivandrum, India. Day light from zenith is allowed and guided through the reflecting optics of the system to properly fill the acceptance cone of the monochromator, which has an effective aperture of F/8.7. The solar Fraunhoffer D-lines (at $5890 \AA$ and $5896 \AA$ ) separated by $\sim 6 \AA$ are located and measured by scanning $\sim 15 \AA$ in the above mentioned wavelength region (Fig. 1a). The $\mathrm{D}_{1}$ absorption line (5896 $\AA$ ) as shown in Fig. $1 \mathrm{~b}$ is chosen for the present study. Near the bottom of $\mathrm{D}_{1}$ absorption line an emission like feature is noticed at every scan. Subtraction of the intensity value at the wing of this feature from that at the peak gives an estimate that is proportional to the intensity of this emission like feature. To show that this feature is the $\mathrm{Na}$ airglow emission, regular scans are performed at every $15 \mathrm{~min}$ on a clear cloud-free day and the above mentioned subtraction is repeated at every scan. The subtracted intensity values are plotted with time as shown in Fig. 2. Later on, for regular daytime observations, wavelength position of the grating is locked at $5896 \AA$ and the temporal variation of the $\mathrm{Na}$ intensity is measured through out the day.

The MWDPM, which uses interference filter as the wavelength selector is capable of making near simultaneous measurements of daytime airglow emissions at three different wavelengths ( $7316 \AA, 7402 \AA$, and $6300 \AA$ ). The $\mathrm{OH}$ airglow emissions at $7316 \AA$ are used for comparing the $\mathrm{Na}$ airglow emissions obtained using the present spectrometer. The technical details of the MWDPM have been described elsewhere (Sridharan et al., 1998).

\section{Results and discussions}

Figure 1a shows the solar Fraunhofer D lines measured by the present spectrometer using $100 \mu \mathrm{m}$ slit width and $5 \AA \mathrm{min}^{-1}$ scan speed. The zoomed in $\mathrm{D}_{1}$ line, which shows an emission like feature is depicted in Fig. 1b. This feature is assumed to be that of the $\mathrm{Na}$ airglow emission, since it sits near the bottom of the Fraunhofer $\mathrm{D}_{1}$ absorption line. Further, to make sure that this is the $\mathrm{Na}$ emission feature, the aforementioned method described in Sect. 2 is followed. The line curve of Fig. 2a, drawn following the procedure of Sect. 2 depicts the temporal variability of the normalized intensity of this emission like feature measured at every $15 \mathrm{~min}$ at the position as shown in Fig. 1b. The emission intensity has been normalized according its maximum value. The curve with square symbols of Fig. 2a shows the temporal variability of the normalized intensity of $\mathrm{OH}$ emission at $7316 \AA$ obtained from the MWDPM. It is obvious from Fig. 2a that these intensity variabilities follow similar trend. To show the degree to which these intensity 
(a)
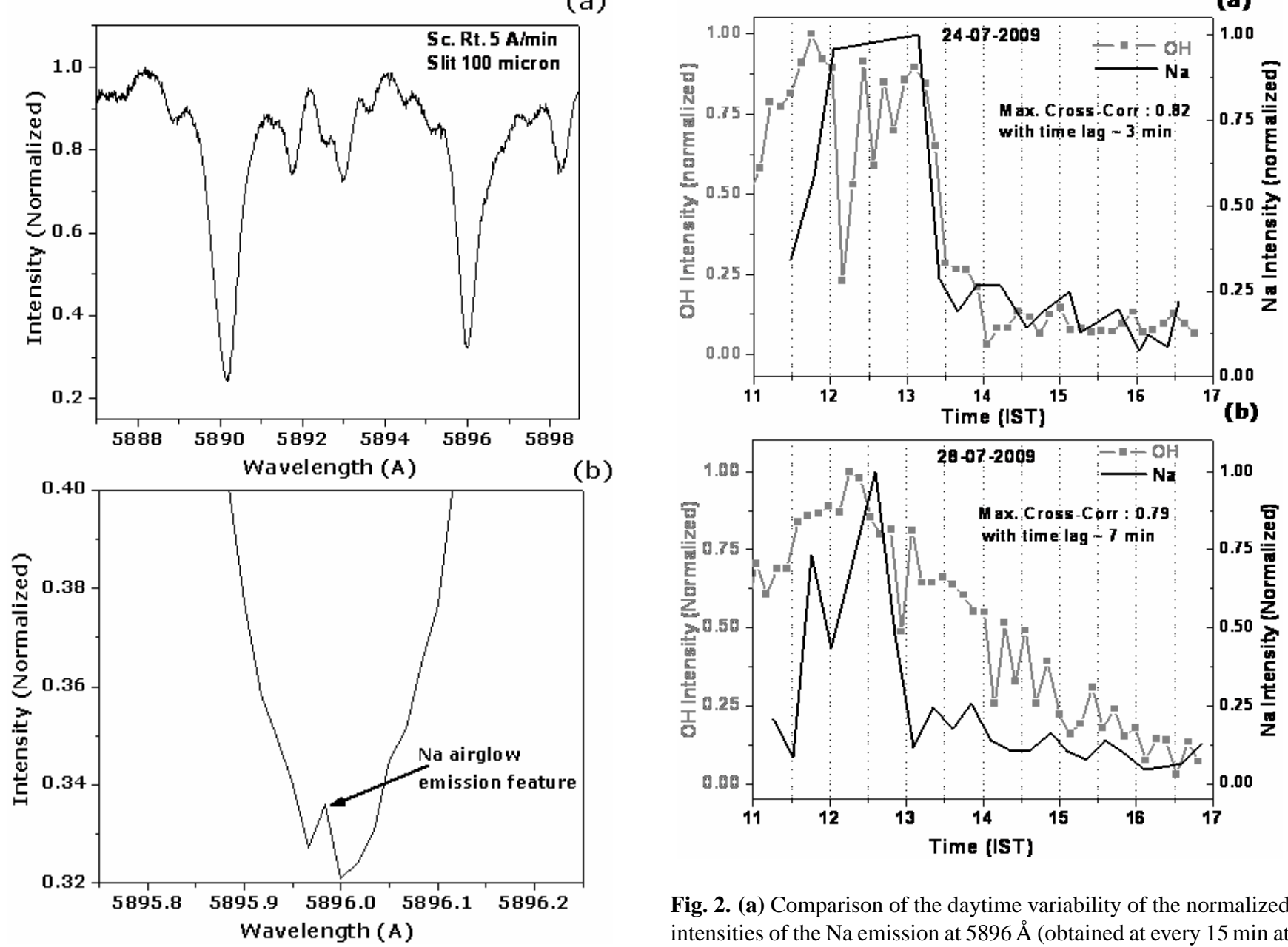

Fig. 2. (a) Comparison of the daytime variability of the normalized intensities of the $\mathrm{Na}$ emission at $5896 \AA$ (obtained at every $15 \mathrm{~min}$ at the positions of the feature as shown in Fig. 1b) and $\mathrm{OH}$ emissions at $7316 \AA$. (b) Same as Fig. 2a but on a different day.

Fig. 1. (a) Solar Fraunhofer D lines (5890 and $5896 \AA$ ) on a clear day measured by the spectrometer using $100 \mu \mathrm{m}$ slit width and $5 \AA \mathrm{min}^{-1}$ scan speed. (b) Zoomed in Fraunhofer D1 line (5896 $)$ which shows the $\mathrm{Na}$ airglow emission feature.

variabilities are correlated, cross-correlation analysis is performed. It is found that the intensity variabilities of Fig. 2a are best correlated (maximum cross-correlation of 0.82) with a time lag $\sim 3 \mathrm{~min}$. Obviously, the intensity variabilities of both the emissions of Fig. 2a, which exhibit short-scale fluctuations, are excellently correlated with slight temporal shift. Figure $2 \mathrm{~b}$ also shows this short-scale fluctuations and their excellent correlation (maximum cross-correlation 0.79 with a delay $\sim 7 \mathrm{~min}$ ) on a different day. Now, it is known that these short-scale fluctuations, which are indicators of the ambient chemical/dynamical processes of the particular region of atmosphere $(\sim 90 \mathrm{~km}$ altitude $)$, are always present in the temporal variability of the airglow emissions. This clearly indicates that the intensities of the feature measured by the spectrometer are of $\mathrm{Na}$ airglow emissions.

Figure $3 \mathrm{a}-\mathrm{d}$, which are presented here to confirm the above observations, depict the comparisons of the normal-

ized intensities of $\mathrm{Na}$ and $\mathrm{OH}$ emissions on four different days. For Fig. 3a, b and d maximum cross-correlations obtained are respectively $0.97,0.87$ and 0.78 with zero time lag. Obviously the $\mathrm{Na}$ and $\mathrm{OH}$ emissions variabilities on these 3 days show excellent correlations without any noticeable time delay. However, the maximum cross-correlation obtained for Fig. $3 \mathrm{c}$ is 0.61 with a time lag $\sim 8.5 \mathrm{~min}$. Hence, it is clear from Fig. $3 \mathrm{c}$ that this particular day shows good correlation but with a small time delay. As shown in Fig. 3, Na emission exhibits significant variability within a day and from one day to another. The short-scale modulations therein indicate the possible role of dynamics and the chemistry.

Further, in order to find out the cause-effect of the dayto-day resemblance/disparity more days data have been analyzed. Presented here in Figs. 4 and 5 are, respectively, the variability of the $\mathrm{Na}$ and $\mathrm{OH}$ emission intensities for 9 days during February 2007. Na emissions on 9th, 14th and 15th exhibit typical diurnal characteristics governed by the movement of sun relative to the measurement site while on rest 

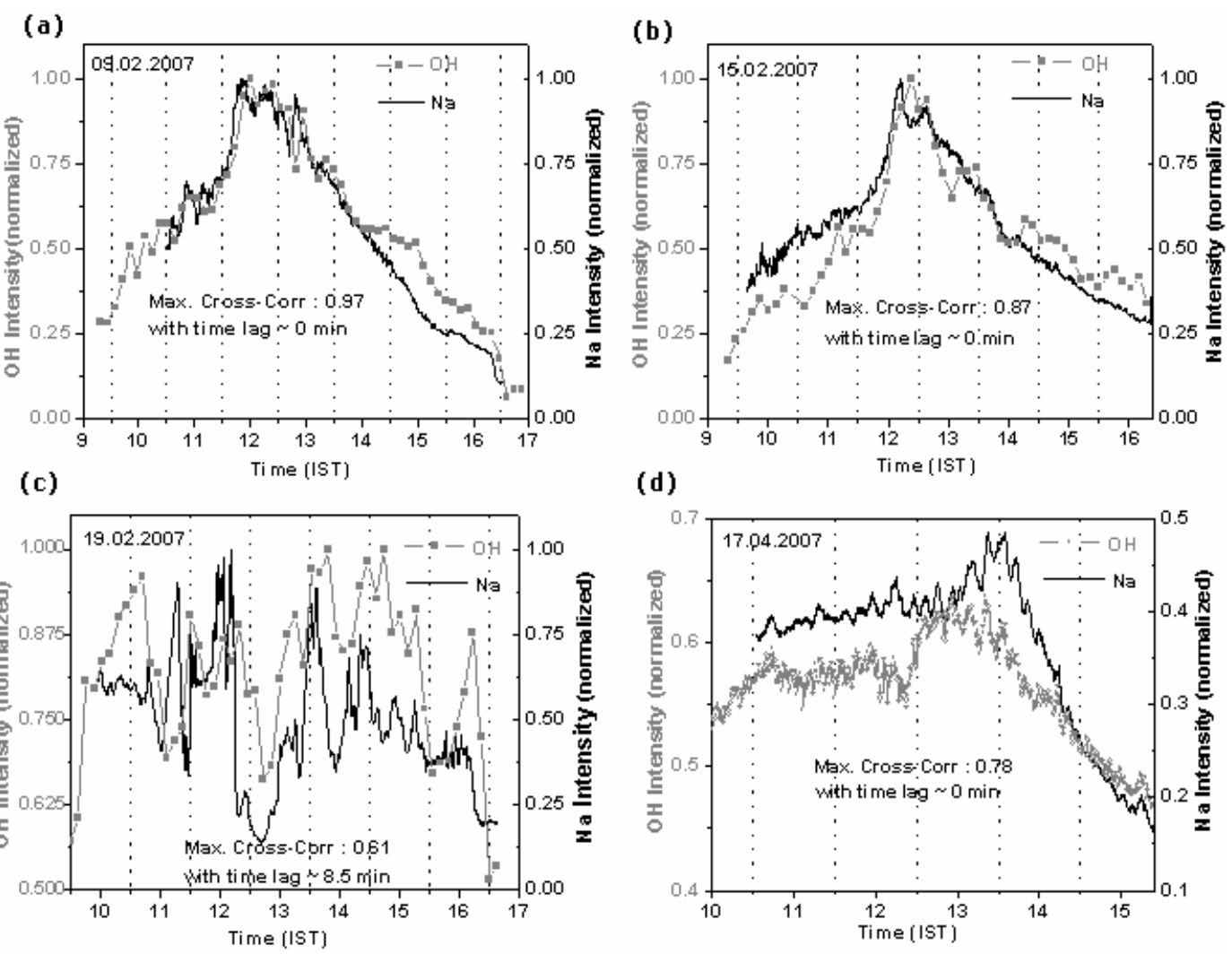

Fig. 3. (a-d) Comparative plot of the temporal variabilities of the $\mathrm{Na}$ and $\mathrm{OH}$ emissions on 4 days during February 2007.

of the days the intensities do not exhibit this diurnal variation. $\mathrm{OH}$ intensities on 9 to 15 February reveal the typical variation of this site, with intensities on 9th, 14th and 15th corroborating with that of the $\mathrm{Na}$ emissions. In post-noon hours of 12th and 13th, variations in the $\mathrm{Na}$ and $\mathrm{OH}$ intensities reveal opposite trends, i.e. the former increases while the latter decreases. This post-noon hours dissimilar variabilities on these two days could be linked to the disparity in the emission layers height variations for the respective emissions. $\mathrm{Na}$ emission on 19th shows very large oscillations that are also seen in the $\mathrm{OH}$ emissions. The wavelet analysis of these emission intensities reveals the presence of gravity waves of periodicity $\sim 1.5 \mathrm{~h}$ as seen in Fig. 6 . Since both the emissions originate from the same altitude regime, signatures of the gravity waves are expected to be the same for both the emissions. This is reflected in the observed oscillations of both the emissions. Signatures of gravity waves in the $\mathrm{Na}$ and $\mathrm{OH}$ airglow emissions have also been reported by many studies in the past (Molina, 1980; Datarange et al., 1984; Medeiros et al., 2003). Na emission intensity on 21 st, 22nd and 23rd exhibits an unusual and fast enhancement at around 11:00 Indian Standard Time (IST). On these days, OH emissions also exhibit a sudden increase around the same time. Obviously, there exist similarities among the variabilities of these emissions.
For daytime $\mathrm{Na}$ airglow emissions, it is well-known that resonant excitation plays the dominant role. On the other hand, daytime $\mathrm{OH}$ emissions owe only to the photo-chemical excitations. Now it has been found that the daytime $\mathrm{Na}$ and $\mathrm{OH}$ emissions variabilities corroborate each other excellently not only in some of the above mentioned days but also on many other days throughout the years. To be more specific, we had simultaneous measurements of $\mathrm{Na}$ and $\mathrm{OH}$ emissions for about 75 days from February 2007 to November 2009. Among these days, about $80 \%$ days show excellent similarities, about $15 \%$ show similar trends and about 5\% show dissimilar variabilities. From these observations, it appears that photo-chemical excitations are also playing important role in the daytime $\mathrm{Na}$ emission variabilities. To investigate the reason behind similar variabilities, let us recollect the Chapman chemical scheme for excitation of $\mathrm{Na}$ atoms as given by Eqs. (1-4) in the "Introduction". On the other hand, daytime $\mathrm{OH}$ emissions owe to the following chemical excitations (Bates and Moiseiwitsch, 1956)

$$
\begin{aligned}
& \mathrm{O}+\mathrm{O}_{2}(+\mathrm{M}) \rightarrow \mathrm{O}_{3}(+\mathrm{M}) \\
& \mathrm{H}+\mathrm{O}_{3} \rightarrow \mathrm{OH}^{*}(v \leq 9)+\mathrm{O}_{2} \\
& \mathrm{OH}^{*}(v \leq 9) \rightarrow \mathrm{OH}+h v \quad(0.5-5 \mu \mathrm{m})
\end{aligned}
$$

where " $v$ " denotes the vibrational states involved in the emission processes. Transitions among the same 


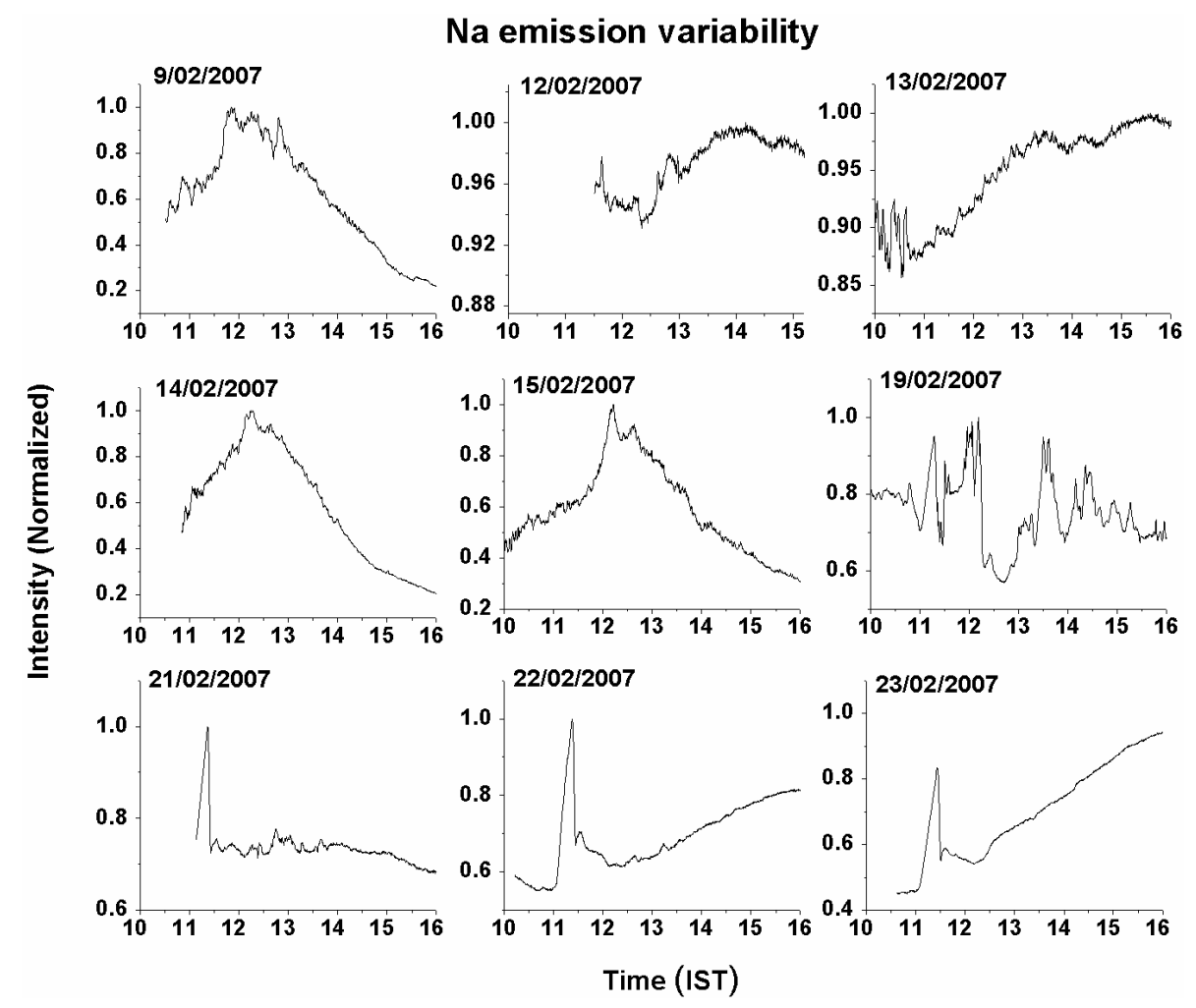

Fig. 4. Temporal variations in the observed Na emission intensities on the 9 days during February 2007.

\section{OH emission variability}

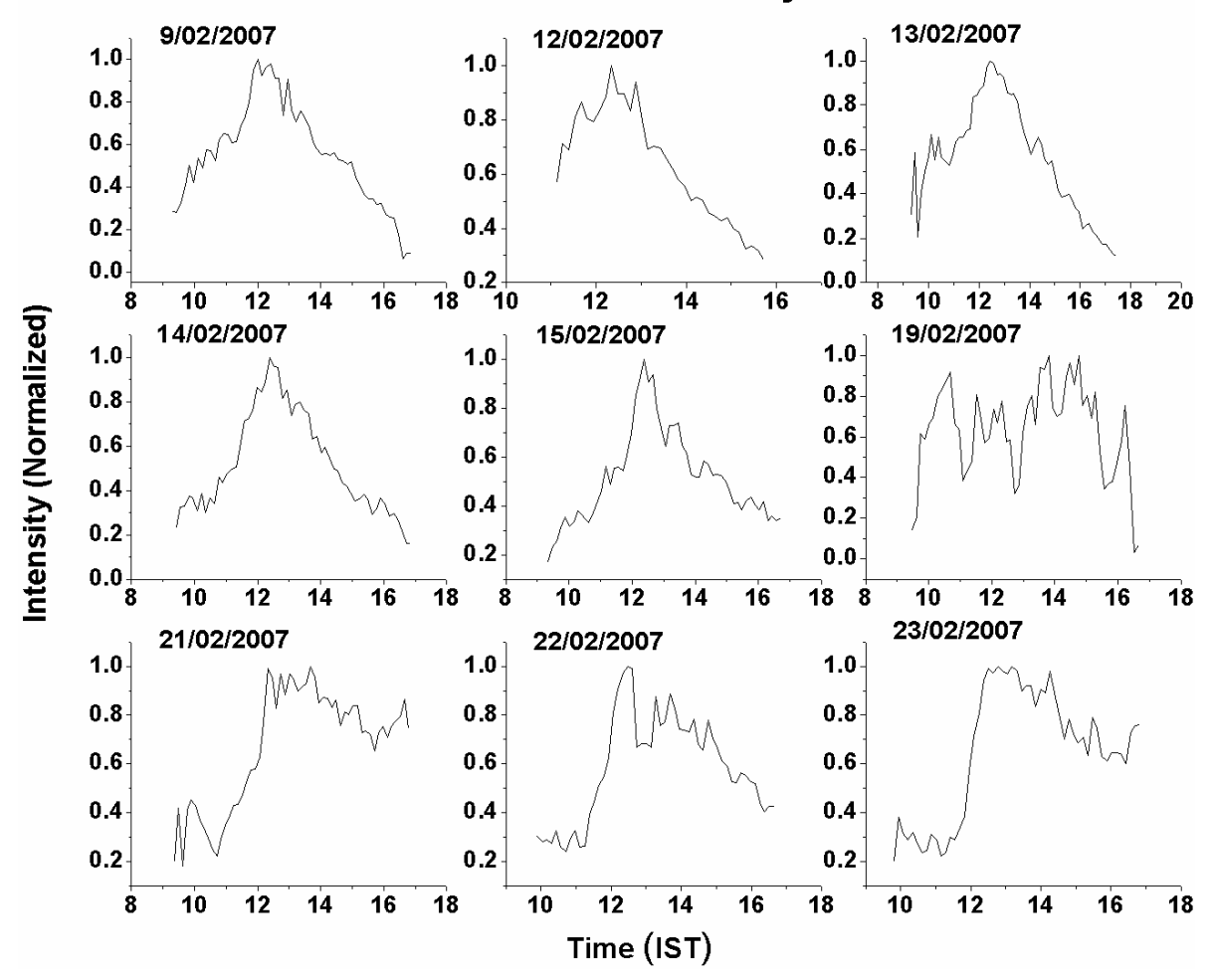

Fig. 5. Same as Fig. 4 but for the $\mathrm{OH}$ emissions. 


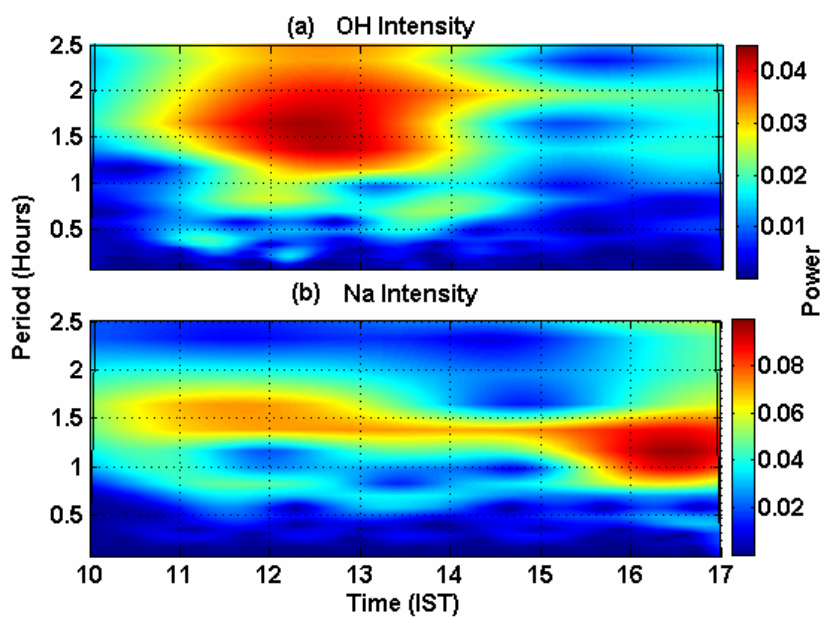

Fig. 6. Wavelet periodograms of (a) OH Intensity and (b) Na Intensity, on 19 February 2007.

vibrational-rotational levels of $\mathrm{OH}$ radicals according to Eq. (7) give rise to the $\mathrm{OH}$ emission. It is obvious from Eqs. (5-7) as well as the Chapman scheme of Eqs. (1-4), $\mathrm{O}$ and $\mathrm{O}_{3}$ play similar role in the excitations of both the $\mathrm{Na}$ and $\mathrm{OH}$ emissions. Also, both the emissions originate from the same altitude region $(90 \mathrm{~km})$ that is significantly influenced by the dynamics i.e. waves and tides of lower atmospheric origin. Being originated from the same region, effect of the dynamical activity is expected to be same for both the emissions. Hence, similar variabilities in these emissions are believed to be due to the similar role played by the [O] and $\mathrm{O}_{3}$ (in their photo-chemical excitations) and the dynamics occurring at the same altitude region.

To consider the errors of measurements involved in the present technique, let us recollect that the measurement is made near the bottom of Fraunhofer $\mathrm{D}_{1}$ absorption line, where Rayleigh scattered light and the terrestrial $\mathrm{Na}$ absorption feature lie apart from the $\mathrm{Na}$ dayglow line emission. Doppler shift of this line emission around the bottom of the absorption line throughout the day could introduce time varying errors in the measurements, but for $\mathrm{Na}$ wavelength since the Fraunhofer line width is quite large in comparison to the Doppler shift, this error can be neglected (Chanin, 1975). However, since the wavelength reproducibility of the present spectrometer is $\sim 0.1 \AA$, during tuning it to the $\mathrm{D}_{1}$ line by scanning, there may occur a maximum wavelength positioning error $\sim 0.1 \AA$ from its actual position. Because of this positioning error the maximum measurement error has been estimated and it is found to vary between $8-10 \%$ from the actual emission intensity. Also the terrestrial $\mathrm{Na}$ absorption feature changes diurnally because of the slant path variation through the Na layer. Depending on the zenith angle variation and the $\mathrm{Na}$ abundance variation there occur variations in the solar radiation absorption, which may introduce a time varying depression of the dayglow signal. It is already known that the percent depression of the dayglow signal is equal to the percent terrestrial absorption (Burnett et al., 1975). Hence, this absorption also is likely to introduce a small measurement error.

More studies have been called for to quantify the roles of $\mathrm{O}, \mathrm{O}_{3}$ and $\mathrm{Na}$ concentrations in explaining the temporal evolution of the $\mathrm{Na}$ emissions. Also the study on the specific role of the dynamics on the $\mathrm{Na}$ emissions over this site is in progress.

\section{Conclusions}

A ground based 1-m scanning monochromator has been used to measure the daytime $\mathrm{Na}$ airglow emissions at $589.6 \mathrm{~nm}$ from Trivandrum, a near-equatorial station in India. The $\mathrm{Na}$ emission intensity exhibits significant variability within a day and from one day to another. Na emission intensity has been compared with the daytime $\mathrm{OH}$ airglow emission at $731.6 \mathrm{~nm}$, which is simultaneously measured using the unique Multiwavelength Dayglow Photometer. On most of the occasions, the temporal variability of the $\mathrm{Na}$ and $\mathrm{OH}$ emissions corroborate each other without any appreciable time delay, although a small time delay up to $\sim 10 \mathrm{~min}$ has been observed from time to time. It appears, in this study that the daytime $\mathrm{Na}$ emission variabilities are influenced too by the photo-chemical excitations. The observed similar variabilities in the $\mathrm{Na}$ and $\mathrm{OH}$ emissions are believed to be due to the similar role played by the $[\mathrm{O}]$ and $\mathrm{O}_{3}$ (in their photochemical excitations) and the dynamics occurring at about the same altitude $(\sim 90 \mathrm{~km})$. It is also found in this study that the dynamics, particularly the gravity waves play important role in producing the short-scale oscillations in these emissions.

Acknowledgements. This work was supported by Department of Space, Government of India. One of the authors C. Vineeth gratefully acknowledges the financial assistance provided by the Indian Space Research Organization.

Topical Editor C. Jacobi thanks P. Ammosov and another anonymous referee for their help in evaluating this paper.

\section{References}

Bates, D. R. and Moiseiwitsch, B. L.: Origin of the Meinel hydroxyl system in the night airglow, J. Atmos. Terr. Phys., 8(6), 305-308, 1956.

Blamont, J. E.: The dayglow of the sodium D lines, J. Geophys. Res., 66(5), 1407-1423, 1961.

Burnett, C. R., Lasher, R. W., Miskin, A. S., and Sides, V. L.: Spectroscopic Measurement of Sodium Dayglow: Absence of a Large Diurnal Variation, J. Geophys. Res., 80(13), 1837-1844, 1975.

Datarange, D. K. and Tillu, A. D.: Gravity waves from sodiumdayglow observations, Adv. Space Res., 4(4), 101-104, 1984.

Chanin, M. L.: Filling in of the Fraunhofer lines by scattering on the ground, J. Geophys. Res., 80(19), 2859-2862, 1975. 
Chapman, S.: Notes on atmospheric sodium, J. Astrophys., 90, 309-316, 1939.

Clemesha, B. R., Kirchhoff, V. W. J. H., and Simonich, D. M.: Simultaneous observations of the $\mathrm{Na} 5893-\mathrm{A}$ nightglow and the distribution of sodium atoms in the mesosphere, J. Geophys. Res., 83, 2499-2503, 1978.

Clemesha, B. R., Kirchhoff, V. W. J. H., Simonich, D. M., Takahashi, H. P., and Batista, P.: Simultaneous observations of sodium density and the $\mathrm{NaD}, \mathrm{OH}(8,3)$, and OI 5577- $\AA$ nightglow emissions, J. Geophys. Res., 84, 6477-6482, 1979.

Clemesha, B. R., Simonich, D. M., Takahashi, H. S., Melo, M. L., and Plane, J. M. C.: Experimental evidence for photochemical control of the atmospheric sodium layer, J. Geophys. Res., 100(D9), 18909-18916, 1995.

Khomich, V. Yu, Semenov, A. I., and Shefov, N. N.: Airglow as an indicator of upper atmospheric structure and dynamics, Springer, 2008.

Kirchhoff, V. W. J. H., Clemesha, B. R., and Simonich, D. M.: Sodium Night-glow Measurements and Implications on the Sodium Photochemistry, J. Geophys. Res., 84(A4), 1323-1327, 1979.

Medeiros, A. F., Taylor, M. J., Takahashi, H., Batista, P. P., and Gobbi, D.: An investigation of gravity wave activity in the low-latitude upper mesosphere: Propagation direction and wind filtering, J. Geophys. Res., 108(D14), 4411, doi:10.1029/2002JD002593, 2003.
Molina, A.: Sodium nightglow and gravity waves, J. Atmos. Sci., 40, 2444-2450, 1983.

Plane, J. M. C.: A time-resolved model of the mesospheric Na layer: constraints on the meteor input function, Atmos. Chem. Phys., 4, 627-638, doi:10.5194/acp-4-627-2004, 2004.

Sarkhel, S., Sekar, R., Chakrabarty, D., Narayanan, R., and Sridharan, S.: Simultaneous sodium airglow and lidar measurements over India: A case study, J. Geophys. Res., 114, A10317, doi:10.1029/2009JA014379, 2009.

Shefov, N. N. and Piterskaya, N. A.: Spectral and space-time characteristics of the background luminosity of the upper atmosphere Hydroxyl emission, in: Aurorae and Airglow, edited by: Galperin, Yu. I., N 31.VINITI, Moscow, 1984.

Slipher, V. M.: Emissions in the spectrum of the light of the night sky, Publ. Astron. Soc. Pacific, 41, 262-265, 1929.

Sridharan, R., Modi, N. K., Raju, D. P., Narayanan, R., Pant, T. K., Taori, A., and Chakrabarty, D.: Multiwavelength daytime photometer-a new tool for the investigation of atmospheric processes, Meas. Sci. Technol., 9, 585-591, 1998.

Takahashi, H. and Batista, P. P.: Simultaneous measurements of $\mathrm{OH}(9,4),(8,3),(7,2),(6,2)$ and $(5,1)$ bands in the airglow, J. Geophys. Res., 86A, 5632-5642, 1981.

Yarin, V. I.: On the dependence of intensity of $\mathrm{OH}$ bands on the rotational temperature, in: Aurorae and Airglow, edited by: Krassovsky, V. I., N8.USSR Academic Science Publishing House, Moscow, 1962a. 